\title{
Injury prevention of student rock climbers based on the formation of rational technique of movements: a randomized control trial
}

\author{
Serhii Kozin ${ }^{1 \mathrm{ABCD}}$, Zhanneta Kozina ${ }^{1 \mathrm{ACD}}$, Marina Jagiello ${ }^{2 \mathrm{ACD}}$, Marko Joksimović ${ }^{3 \mathrm{ACD}}$ \\ ${ }^{1}$ H.S. Skovoroda Kharkiv National Pedagogical University, Kharkiv, Ukraine \\ ${ }^{2}$ Gdansk University of Physical Education and Sport in Gdansk, Poland \\ ${ }^{3}$ Institute of Sports and Sports Medicine, Montenegro
}

Authors' Contribution: A - Study design; B - Data collection; C - Statistical analysis; D - Manuscript Preparation; E - Funds Collection.

\section{Abstract \\ Background and Study Aim}

Material and Methods

Results

Conclusions

\section{Keywords:}

Students are often injured while playing sports. The main condition for preventing injuries is the correct technique of movements. In the literature, rock climbing has not been analyzed in terms of prevention of student injuries. Therefore, the development of programs to prevent injuries of students-rock climbers is relevant. Aim: to determine the impact of the use of exercises in a closed kinematic chain on the technical skill and the number of injuries to the elbows of student-rock climbers based on the analysis of the onearm hang technique.

First, to substantiate the correct technique in rock climbing, the technique of performing one-arm hang was analyzed by 20 leading male climbers of Ukraine and 20 students - novice male climbers. Then a randomized control study was conducted. The participants in the randomized control study were 40 male students-climbers in the intervention group and 44 male students-climbers in the control group aged 1819 years. The one-arm hang technique was determined based on the angles between the shoulder and the collarbone during the movement. The experiment lasted 1 year. At the beginning and at the end of the experiment, the analysis of the one-arm hang technique was carried out. The number of elbow injuries in both groups was also recorded.

The main parameters of the one-arm hang technique for qualified and unskilled climbers have been substantiated. For qualified climbers, one-arm hang involves the muscles of the shoulder girdle, torso, and legs. In unskilled climbers, one-arm hang is provided only by the muscles of the arm. In a control randomized study, there was a significant improvement in the results of biomechanical analysis of the hang technique in athletes in the intervention group $(p<0.001)$. The use of exercises in a closed kinematic chain significantly reduces the incidence rate of elbow injuries in student-climbers $(p<0.05)$. The odds rate of mild elbow injuries in the control group was 4.625 times higher than the intervention one $(95 \% \mathrm{Cl}$ : $1.198 ; 17.854)$, the odds rate of moderate injuries in the control group was 5.588 times higher than in the control group than the intervention one (95\% Cl: $1.143 ; 27.324)$.

Exercises in closed kinematic chains are an effective means of improving climbing technique and injury preventing to university students during rock climbing.

kinematic chain, training, trauma, elbow, bouldering

\section{Introduction}

Currently, the importance of physical culture and sports is increasing. Sports activities contribute to the increase of motor intelligence, the development of psychological qualities. This is necessary for building a career, showing individuality, and being successful in all areas of activity. Sports activities are of particular relevance for students. However, sports are also accompanied by injuries of varying degree. This leads to spending a lot of time to recover from injuries, skipping classes, and psychological problems [1-4]. In this regard, the problem of student injuries during sports is widely covered in modern literature according to the databases Endnote, Web of Science, Scopus, PubMed. This indicates the high urgency of this problem in the world [5-7].

Clifton et al. [5] described the epidemiology of injuries sustained in basketball by high school girls in the period

\footnotetext{
๑) Serhii Kozin, Zhanneta Kozina, Marina Jagiello,

Marko Joksimović, 2021

doi:10.15561/20755279.2021.0507
}

from 2005-2006 to 2013-2014 school years and student women's basketball in the period from 2004-2005 to 2013-2014 school years. Clifton et al. [5] concluded that the injury rate was higher in students than in high school students, and higher in competition than in training. In a study by Fraser et al. [6] is described the epidemiology of ball contact injuries in 11 sports associations (men's football, women's field hockey, women's volleyball, men's baseball, women's softball, men's and women's basketball, men's and women's lacrosse, men's and women's football), in the period from 2009-2010 to 20142015 academic years. The percentage of ball contact injuries was highest in women's softball, women's field hockey, and men's baseball. Although more than half were injuries without wasting time, such serious injuries as concussions and fractures were reported.

Hurtubise et al. [7] conducted a study of gender differences in severe injuries in various sports. Hurtubise et al. [7] concluded that women are at increased risk of severe injury, especially concussion, and this should be 
taken into account when planning preventive measures. Jin [8] found that college students were injured when they were playing football. It was revealed that every student is an athlete, on average involved 1.6 different sports. The average number of hours of sports per year was 371.6 hours, respectively. The average total number of sports injuries sustained by athletes was 1.7 per participant, $80.8 \%$ of respondents reported having at least one sports injury. Thus, the number of injuries among students involved in sports is high.

The data of other authors also testify to the high injury rate of students involved in sports [9-11]. The authors $[12,13]$ note the high prevalence of injuries among students involved in various sports. In most studies, traumatic exposure was defined as the participation of one student-athlete-amateur in one workout or game, and was expressed as an exposure on the athlete (AEs). This value ranges from 1.82 to 15.29 per 1000 student-athletes who participated in training or games (AEs). Moreover, women are more likely to be injured than men. The most traumatic sports are team ball sports and wrestling.

From the point of view of students' injuries prevention rock climbing were not analyzed. However, at present, this sport is becoming more and more popular among students in connection with the acquisition of the status of Olympic sport [14]. Therefore, a promising direction, in our opinion, will be the analysis of injuries among students involved in rock climbing, and the development of injury prevention programs.

Injury prevention is based on the correct technique of movements $[15,16]$. The correct technique of physical exercise is a way of its implementation, where the motor task is solved most efficiently and rationally [17]. Correct technique assumes energy efficiency of movement. It determines the economy of energy and creates the opportunity to achieve the highest results for the athlete. Performing movements in the most rational way prevents injury. At the same time, conditions are created for biomechanically expedient work of the locomotor apparatus.

The theory of one of the classics of biomechanics, Bernshtein [18-20], testifies that the basis of injury prevention is the effective organization of movement control from the side of the central nervous system. Improvement of the organization of movement control is carried out with the help of neuromuscular training [21, 22]. One of the important components of neuromuscular training programs for injury prevention is exercise in a closed kinematic chain [21-24]. Coppack et.al. [21] showed the effectiveness of closed chain exercises compared to open chain exercises in preventing injury. Augustsson et.al. [22] also revealed the effectiveness of exercise in a closed kinematic chain compared to exercises in an open kinematic chain to gain muscle mass and increase the jump up. Lee et.al. [23] showed that inward movement of the chin in a closed kinetic chain is more effective in activating the deep flexor of the neck than in an open kinetic chain. Roh et.al. [24] found that exercise in a closed kinetic chain is a more effective therapeutic intervention than exercise in an open kinetic chain. This fact was found to improve the sensorimotor function of the lower extremities and gait functions such as gait speed and symmetry.

In our previous studies [25, 26], it was shown that when one-arm hang is performed in bouldering, the angle between the shoulder and the clavicle should be about 90120 degrees. In this case, more muscles are involved to provide one-arm hang. If the angle is greater, then the hang is provided mainly by the ligaments of the shoulder and elbow. This is dangerous for the ligaments and can lead to injury. In addition, with proper hanging, the muscles of the trunk and legs are included. This helps the muscles of the shoulder girdle work. In this case, a kinematic chain is created, consisting of links: fingers, forearm, shoulder, trunk, legs. At a steep angle, the chain consists of a small number of links without involving the muscles of the trunk and legs. Exercises in a closed kinematic chain allow to use all its links. Thus, the conditions are created for the formation of the skill of working with the whole body to ensure the correct one-arm hang. We think that Closed Kinetic Chain exercises are more effective for climbing than other sports. Climbing is work exclusively in a closed kinetic chain.

Based on this, we formulated a hypothesis: in closed kinematic chains the use of exercises will contribute to the formation of a rational one-arm hang technique in climbing and prevent injuries.

Aim: to determine the influence of the use of exercises in closed kinematic chains on technical skill and the number of injuries to the elbows of students-climbers based on the analysis of the technique of performing onearm hang.

\section{Material and methods}

\section{Participants and randomization}

At the first stage of the study, to substantiate the correct technique in rock climbing, the technique of performing one-arm hang was analyzed by 20 leading male climbers of Ukraine and 20 male students - novice climbers. The age of all athletes was $22.4 \pm 3.2$ years, body length $178.5 \pm 12.5 \mathrm{~cm}$, body weight $-72.2 \pm 8.5 \mathrm{~kg}$.

At the second stage, a randomized control study was conducted. The participants of this study were 84 male students, who were engaged in rock climbing at the amateur level in the cities of Ukraine, aged 18-19 years. All athletes gave written consent to participate in the experiment. The health status of the athletes was monitored during the first 2 weeks of the study using routine medical examinations conducted by a doctor. The athletes were also followed for 6 months to assess the baseline injury frequency and the baseline level of onearm hang technique [27-30].

An independent statistician randomized the athletes in parallel to a control group and an intervention group using a random distribution method using online random number generator program. As a result of randomization, 40 athletes were assigned to the intervention group and 44 athletes - to the control group. 
The groups were compared in terms of body length, body weight, rock-climbing experience, indicators of one-arm hang technique according to expert judgment, the results of biomechanical analysis, and the number of injuries before the start of the experiment within 6 months. For all these indicators, the groups did not significantly differ among themselves ( $p>0.05$ ). The body length of the athletes in the control group was $172.5 \pm 8.5 \mathrm{~cm}$, the body weight of the athletes in the control group was $65.2 \pm$ $6.5 \mathrm{~kg}$. The body length of the athletes in the intervention group was $173.4 \pm 8.7 \mathrm{~cm}$, the body weight of the athletes in the intervention group was $66.1 \pm 6.6 \mathrm{~kg}$ ( $\mathrm{p}>0.05)$. The groups trained according to the generally accepted plan 3-4 times a week, the number of training hours was the same in both groups. At the beginning and at the end of the experiment, independent experts analyzed the onearm hang technique. The number of elbow injuries in both groups was also recorded. The baseline rate of all elbow injuries recorded within 6 months prior to the experiment was 11 in the control group and 15 in the intervention group.

We have presented the injury rate as the number of injuries per 1000 AEs. We defined AEs as the number of athletes multiplied by the number of all training sessions in which they participated (AEs $=$ athlete $\times$ exposure (training, competition)) [30]. In our case, the number of trainings and competitions was the same in the Control Group and Intervention Group and was 75 before the experiment and 150 during the subsequent experiment for 1 year. The number of climbers in our case was 40 for the Intervention Group and 44 for the Control Group. The injury rate was defined as the number of injuries per 1000 AEs [30].

The number of AEs in the 6 months prior to the experiment was 3300 in the control group and 3000 in the intervention group. The risk of injury per 1000 AEs in the control group and in the intervention group for mild, moderate, and severe injuries did not differ significantly (Table 1).

Procedure

At the first stage of the study, the technique of onearm hang in bouldering was analyzed by 20 leading climbers of the World and Ukraine and 20 novice athletes. Based on the analysis of the technique for performing this movement by athletes, the main characteristics of the correct technique for performing one-arm hang were compiled. The correct (typical for qualified climbers) and incorrect (typical for unskilled climbers) hanging technique were recorded using a Sony FDR-X3000 video camera. Then, using the Kinovea 0.8 .15 computer program, the kinematic characteristics of two models of technique were analyzed (model 1 is typical for beginner athletes, model 2 is typical for qualified athletes) based on the determination of the angles between the shoulder and the clavicle. The analysis of angles was carried out from the moment of grabbing the toe to stable fixation of the hang $(t=30 \mathrm{~s}$, the number of analyzed frames was 10 , the frames were selected at regular intervals; the total number of analyzed attempts was 20 for each model of equipment). A comparative characteristic of the values of the measured angles at the point of stable fixation of the hang was carried out on the basis of 20 measurements for each model of equipment. A biomechanical analysis of two models of technology was carried out on the basis of the laws of classical mechanics (the relationship of forces acting on a body during tension; interaction of forces in kinematic chains). On the basis of a comparative biomechanical analysis of two models of technique, the main biomechanical characteristics of the correct hanging technique in rock climbing were given.

At the second stage, elbow injuries were recorded in the formed groups of climbers (control group and

Table 1. Comparison of injuries of elbows of rock-climbers between the Control $(n=44)$ and the Intervention Groups $(n=40)$ within six months before the experiment

\begin{tabular}{|c|c|c|c|c|c|c|c|c|}
\hline \multirow[b]{2}{*}{ Injury Degree } & \multicolumn{3}{|l|}{ Control Group } & \multicolumn{3}{|c|}{ Intervention Group } & \multirow{2}{*}{$\begin{array}{l}-\operatorname{IRR}(95 \% \mathrm{Cl})^{\mathrm{a} b \mathrm{~b}} ; \\
\operatorname{ORR}(95 \% \mathrm{Cl})^{\mathrm{c}}\end{array}$} & \multirow[b]{2}{*}{ p Value } \\
\hline & Injuries, No. & $\begin{array}{l}\text { AEs, } \\
\text { No. }\end{array}$ & $\begin{array}{l}\text { Injury } \\
\text { Rate }^{a}\end{array}$ & $\begin{array}{l}\text { Injuri } \\
\text { No. }\end{array}$ & $\begin{array}{l}\text { AEs, } \\
\text { No. }\end{array}$ & $\begin{array}{l}\text { Injury } \\
\text { Rate }\end{array}$ & & \\
\hline & & & & & & & $1.047(0.870 ; 0.1259)^{a}$ & \\
\hline \multirow[t]{3}{*}{ Mild } & 6 & 3300 & 1.82 & 7 & 3000 & 2.33 & $0.779(0.286 ; 2.124)^{b}$ & $0.425^{d}$ \\
\hline & & & & & & & $0.744(0.227 ; 2.437)^{c}$ & \\
\hline & & & & & & & $1.043(0.882 ; 1.233)^{a}$ & \\
\hline \multirow[t]{3}{*}{ Moderate } & 5 & 3300 & 1.52 & 6 & 3000 & 2.00 & $0.758(0.250 ; 2.292)^{b}$ & $0.432^{d}$ \\
\hline & & & & & & & $0.726(0.203 ; 2.594)^{c}$ & \\
\hline & & & & & & & $1.047(0.870 ; 0.1259)^{a}$ & \\
\hline \multirow[t]{2}{*}{ Severe } & 1 & 3300 & 0.91 & 2 & 3000 & 1.33 & $0.779(0.286 ; 2.124)^{b}$ & $0.425^{d}$ \\
\hline & & & & & & & $0.744(0.227 ; 2.437)^{c}$ & \\
\hline
\end{tabular}

NOTE: AEs - athlete $\times$ exposure (training sessions, competitions); Injury rate indicates the number of injuries per

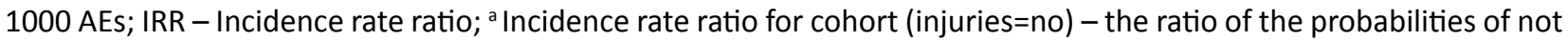
getting injured in the control group and the intervention group; ${ }^{b}$ Incidence rate ratio for cohort (injuries $=$ yes) - the ratio of the probabilities of not getting injured in the control group and the intervention group; ${ }^{\mathrm{C}}$ ORR - Odds Rate Ratio for group (control / intervention); $\mathrm{Cl}$ - confidence interval (Lower bound; Upper bound); ${ }^{\mathrm{d}}$ By Fisher exact test 
intervention group) for 6 months to determine the initial level of injury. Then an experiment was carried out, which lasted 1 year. The groups trained according to the generally accepted plan 3-4 times a week. The number of training sessions was the same in both groups during the year and amounted to 150 trainings. In the intervention group, the developed injury prevention program was applied. At the beginning and at the end of the experiment, analysis of the one-arm hang technique was carried out according to both the expert judgment and the results of biomechanical analysis in both groups. The number of elbow injuries in both groups was also recorded.

Method for determining the level of technical skill of athletes

The method of biomechanical analysis of the hanging technique in rock climbing was used to analyze the hanging technique: 1 - qualified $(n=20)$ and unskilled $(n=20)$ athletes; 2 - students of the control group $(n=44)$ and the intervention group $(n=40)$. Using the computer program Kinovea 0.8 .15 , the kinematic characteristics of the one-arm hang technique in rock climbing were analyzed. One-arm hang was chosen for the analysis of the technique due to the fact that this element is the basis for other technical elements in rock climbing. Also, the technique for performing this element was substantiated in our previous studies $[25,26]$. The one-arm hang technique was determined based on determining the angles between the shoulder and the collarbone. The angles were analyzed from the moment the toe was gripped to stable fixation of the hang $(\mathrm{t}=30 \mathrm{~s}$, the number of analyzed frames was 10 , the frames were selected at regular intervals). For each athlete, 5 attempts were analyzed, the arithmetic mean of 5 attempts was taken as the analyzed indicator.

Technical proficiency was also determined by expert judgment. The technique of hanging on one hand was evaluated by four experts - leading rock climbing coaches in Ukraine. The assessment was carried out on a 12-point system. The sum of the points given by all four experts was used.

\section{Trauma registration method}

Cases of injuries and diseases of the elbows were recorded in both groups, first for 6 months to determine the initial level of injuries, and then during the year of the experiment. The following injuries were recorded: mild, moderate, severe. Mild injuries included those that heal in less than 1 month, moderate injuries - those that heal in 2-3 months, and severe injuries - those that heal within 6-12 months. Injuries were recorded by interviewing athletes and coaches.

\section{Intervention program}

The basic program, according to which the control group and the intervention group were trained, were the same. In the Intervention Group, athletes performed our proposed additional Exercises in a closed kinematic chain. The exercises were performed at each workout (3-4 times a week). The intervention program took 15 minutes for each workout. Athletes and coaches recorded the use of the intervention program in their diaries.

We used Exercises in a closed kinematic chain in the
Intervention Group. In our previous studies [25, 26], it was shown that when hanging on one arm in bouldering, the angle between the shoulder and the clavicle should be about 90-120 degrees. In this case, more muscles are involved to provide hang. This helps the muscles of the shoulder girdle work. In this case, a kinematic chain is created, consisting of links: fingers, forearm, shoulder, trunk, legs. With proper hanging, the muscles of the trunk and legs are turned on. If the angle is greater, then the hang is provided mainly by the ligaments of the shoulder and elbow. This is dangerous for the ligaments and can lead to injury. At a steep angle between the shoulder and the collarbone, the chain is made up of a small number of links without involving the muscles of the trunk and legs. Exercises in a closed kinematic chain allow you to use all its links. Thus, conditions are created for the formation of the skill of working with the whole body to ensure the correct hang.

Exercises in a closed kinematic chain [28]:

1. Push-ups on the rings. Starting position: support with two straight arms on the gymnastic rings face down, feet on toes, the spine is straight. Flexion and extension of the arms with an emphasis on the rings. Keep your spine straight, do not lift your feet off the floor. The number of repetitions is 10-20 times, depending on the level of preparedness of the students. The height of the rings is $100-150 \mathrm{~cm}$, depending on the preparedness of the students.

2. Pull-up in support. Starting position: hold on to a horizontal bar with a height of 150-180 cm, face up, arms straight, feet on the floor. The spine is straight. Flexion and extension of the arms. Keep your spine straight without lifting your feet off the floor. The number of repetitions is 10-20 times, depending on the level of training of students.

Exercises in closed kinematic chains act completely on the entire kinematic chain, more evenly distribute the load on all links of the chain [24, 25]. The program also involved a conscious focus on the inclusion of all muscles of the closed kinematic chain in the process of performing each movement.

\section{Statistical analysis}

To determine the influence of the developed technology on the risk of injury, the following indicators were determined: the reliability of differences between the control group and the intervention group based on the results of expert assessment and biomechanical analysis of the one-arm hang technique, the number of injuries, the risk of injury, the likelihood of injury, relative risk and odds ratio using the computer program SPSS-17, option Crosstabs.

We presented the injury rate as the number of injuries per $1000 \mathrm{AEs}$, and we defined AEs as the number of athletes multiplied by the number of all training sessions in which they participated (AEs $=$ athlete $\times$ exposure (training, competition)) [30]. The injury rate was defined as the number of injuries per 1000 AEs [30].

We used Fisher's exact test and Pearson's Chisquare test to compare injury rates between intervention 
and control groups. We considered a two-sided $\mathrm{p}<0.05$ statistically significant. The significance of differences in the number and risk of injuries between the control group and the intervention group was determined using Fisher's exact test and Pearson's Chi-square test [30].

The risk (probability) of injury (Incidence rate) was defined as the ratio of the number of injuries to the total number of athletes in the analyzed group. The relative risk (Incidence rate ratio) was determined according to the recommendations of the authors [30]. The relative risk (relative probability) (Incidence rate ratio) of injury was determined in two ways: 1 - the ratio of the probability of not getting injured in the control group and the intervention group (notation: Incidence rate ratio for cohort (injuries $=$ no)); 2 - the ratio of the probability of injury in the control group and the intervention group (symbol: Incidence rate ratio for cohort (injuries $=$ yes)). The odds rate of injury was determined as the ratio of the number of injuries to the number of non-injured athletes in the analyzed group [30]. Odds Rate Ratio was defined as the ratio of the chance of injury in the control group to the chance of injury in the intervention group. The relative chances (Odds Rate Ratio) of injury were determined according to the recommendations of the authors [30]. These indicators were determined separately for all types of elbow joint injuries analyzed (Mild, Moderate and Severe).

To assess the influence of the developed program on the level of technical skill of athletes, the groups were compared according to the Student's t-criterion before the experiment and after the experiment in terms of the angle between the shoulder and the collarbone when they performed one-arm hang and in terms of expert assessment of the technique. The groups were preliminarily tested for all indicators for normal distribution according to the Kolmogorov-Smirnov test. No significant differences were found between the obtained distribution and the normal distribution $(p>0.05)$. This gave us the opportunity to apply parametric statistical methods to determine the significance of differences and the relationship between expert judgment of technique and the angle between the shoulder and collarbone. The Pearson correlation coefficient was determined between the expert assessment of the technique and the angle between the shoulder and the collarbone when performing one-arm hang in rock climbing.

The influence of the prior art on the number of injuries was determined by the method of Cochran and MantelHansel. The state of the art below the average by expert judgment (less than 25 points) in combination with the values of the angle between the shoulder and the clavicle (more than 120 degrees) is conventionally designated as 1 ; The level of technology above the average according to expert judgment (more than 25 points) in combination with the values of the angle between the shoulder and the clavicle (less than 120 degrees) is conventionally designated as 2 .

\section{Results}

Justification of the correct one-arm hanging technique

\section{in rock climbing}

The analysis of the hanging technique in rock climbing by athletes of different qualifications showed the presence of two models of the technique for performing this movement, differing in the main parameters. Demonstration of these models of technology is shown in Figure 1 $(1,2)$. Figure 1 (1) shows the first model of the hanging technique in rock climbing. It is characterized by minimal muscle tension in the shoulder and back, a large angle between the shoulder and the collarbone (146 degrees), and an almost vertical position of the lower spine with curvature in the upper spine. This type of technique is typical for unskilled athletes. Figure 1 (2) shows the second model of the hanging technique in rock climbing. This model is characterized by muscle tension in the shoulder, back, and a smaller angle between the shoulder and the collarbone (90 degrees). The second model of technique is typical for qualified athletes.

These differences are due to the more pronounced work of the muscles of the trunk, legs, shoulder in the second model compared to the first model (Fig. 1-3). Since the second model (qualified athletes) is characterized by a pronounced work of the muscles not only of the upper limb, but also of the trunk, legs, it can be concluded that the second model requires the development of these muscles, and cannot be used by low-skilled athletes due to insufficient development of the muscular apparatus. In the first model, hanging is carried out mainly due to the ligamentous apparatus of the joints of the shoulder girdle with minimal involvement of muscles, which is dangerous by injury to the ligaments of the shoulder and elbow joints. In the second model, the hang is also provided by the inclusion of the muscles of the trunk and legs, which reduces the load on the ligamentous apparatus and reduces the likelihood of injury to the ligaments of the shoulder and elbow joints.

We analyzed both models of hanging technique in rock climbing from the point of view of the laws of physics (Fig. 2) and the peculiarities of the interaction of forces in closed kinematic chains (Fig. 3). We schematically presented the distribution of stress when performing a hang in the form of interconnected elements. This "structure" is attached by one link to the upper support (d), and is in a hanging state (Fig. 2). Figure 2 (1) shows a diagram of the first model of the hang technique, and Figure 2 (2) shows a diagram of the second model of hang performance. The first model of the hang technique is characterized by a minimal inclusion of the muscles of the shoulder girdle, trunk, legs; therefore, the area (b) of the connection of the links $(\mathrm{a}, \mathrm{c})$ is relatively small. The second model of the hanging technique in rock climbing is characterized by a larger area (b) of the connection of the links $(a, c)$ with each other due to the inclusion of a greater number of muscles of the shoulder girdle, trunk, legs.

From the point of view of the balance of forces acting on the body $[25,26]$, these models are the same: in both cases, the body weight, which is the product of body mass (m) and gravitational acceleration ( $\mathrm{g}$ ), is held in the hang 
by the force of fixation on the support, which is equal to the reaction force of the support Fp (formula 1):

$$
\mathrm{mg}+\mathrm{Fp}=0
$$

where: $\mathrm{m}$ - body weight, $\mathrm{g}$ - acceleration of gravity, Fp the force of fastening on the support, equal to the reaction force of the support

However, if we consider these models from the point of view of the regularities that determine the preservation of the structure under tension, then these models have significant differences. These differences are due to the laws of mechanics the tensile or compressive strength of materials [25].

According to the basic law of strength conditions, normal stresses $\sigma$ arise in the sections of the bar during tensile or compressive deformation. The longitudinal force $\mathrm{N}$ is related to the normal stress $\sigma$ by the following relationship (formula 2 ):

$$
\sigma=\mathrm{N} / \mathrm{A}
$$

where: $\sigma$ - normal stress; $\mathrm{N}$ - the longitudinal force in the cross section of the rod; $\mathrm{A}$ - the cross-sectional area of the bar.

According to formula 2, the stress arising from hanging in climbing $(\sigma)$ depends on the longitudinal force, that is, on the body weight $(\mathrm{N})$, and on the crosssectional area (A), that is, on the muscles and ligaments of the shoulder girdle that ensure the execution of the hang. The body weight $(\mathrm{N})$ is the same in the first and second models, but the cross-sectional area (A) is larger in the second model. Accordingly, the stress $(\sigma)$ is greater in the first model compared to the second, since to formula 2:

$$
\mathrm{A} 1<\mathrm{A} 2, \mathrm{~N} 1=\mathrm{N} 2, \mathrm{t} \text { herefore } \sigma 1>\sigma 2
$$

The higher efficiency of model 2 (typical for qualified athletes) can also be explained in terms of the addition of forces in the kinematic chain (Fig. 3).

In the first model of the technique, the total force ensuring the execution of the hang is equal to the sum of the forces F1, F2. In the second model of the technique, the number of chain links involved in the movement is greater than in the first. In this case, all the links of the kinematic chain are involved in maintaining the entire structure in the hang. Working muscles determine the action of the forces F1, F2, F3, F4. As a result, the total force ensuring the execution of the hang is equal to the sum of the forces F1, F2, F3, F4.

In general, the addition of forces in the presented kinematic chains can be represented as a formula (formula 3):

$$
\mathrm{F}_{\Sigma}=\Sigma \mathrm{Fi}
$$

where: $\mathrm{F}_{\Sigma}$ - the force holding the body in the hang; Fi - force due to the inclusion of individual interconnected links of a closed kinematic chain; Fp - the reaction force of the support.

In the second model, the total force providing the hang position is significantly greater than the given force in the first model. This means that in the second model, not only the muscles of the upper limb (as in the first model), but also the muscles of the trunk and legs are involved in maintaining the hanging position. Accordingly, the upper limb has a lower load compared to the first model of equipment. This determines the effectiveness of the second model of the technique and provides the basis for the formation of the most effective technique of movements in rock climbing and prevention of injuries.

These provisions became the basis for the development of a program to prevent injuries of students during rock climbing lessons. The program was aimed at developing the correct hanging technique in rock
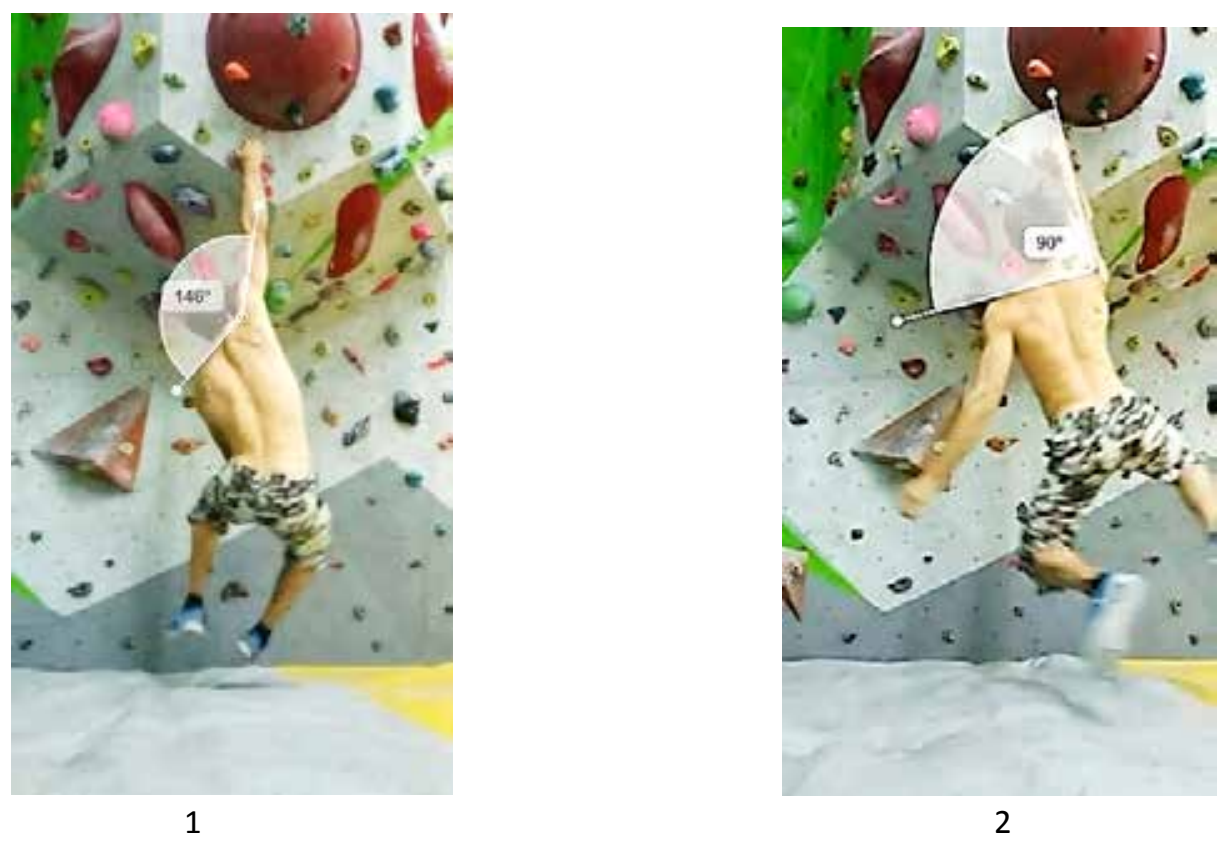

Fig. 1. The phase of fixing the hang in rock climbing, model of technique 1, is typical for beginners (1) and model of technique 2 , is typical for qualified athletes (2) competition) 

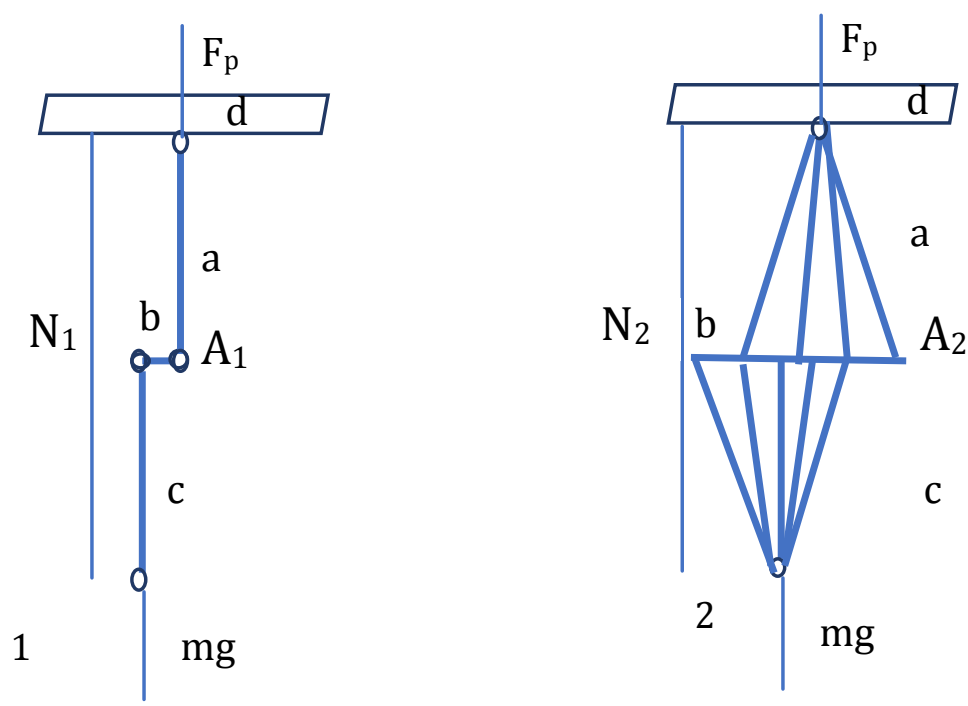

Fig. 2. Diagrams of models of stress distribution when hanging in rock climbing (bouldering): 1 - model 1 (wrong technique, typical for novice athletes); 2 - model 2 (correct technique, typical for qualified athletes); a - the upper part of the chain (upper limb); $b$ - connection of the upper and lower parts of the chain; $c$ - the lower part of the chain (trunk); $\mathrm{d}$ - support (climbing stand); $\mathrm{N}$ is the longitudinal force in the cross section of the rod; $\mathrm{A}$ - cross-sectional area of the rod (muscles and ligaments at the junction of the shoulder and trunk)
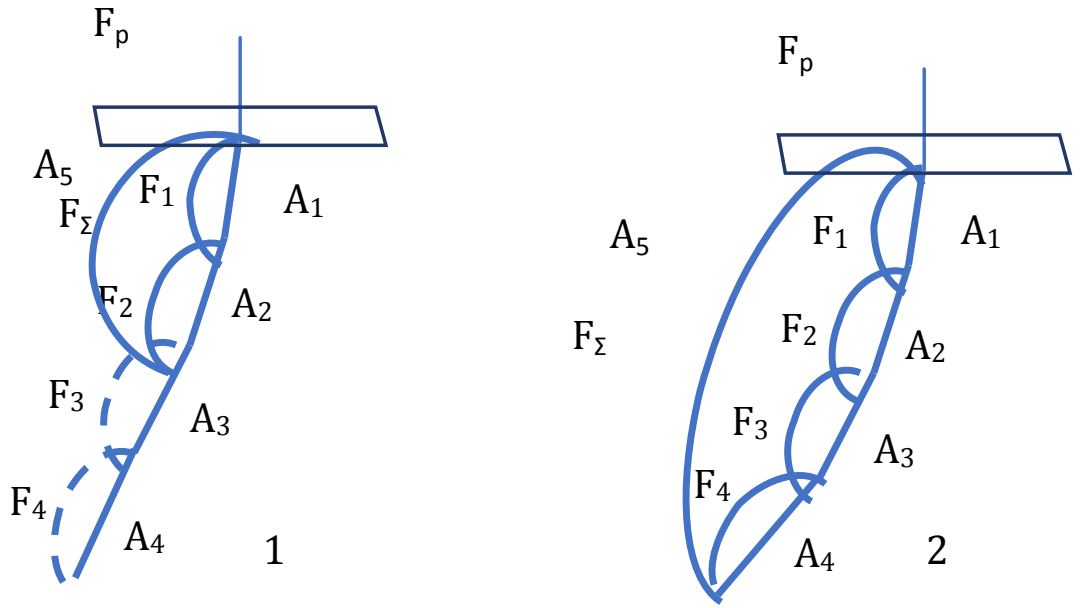

Fig. 3. Diagram of the kinematic chain in various models of hanging in rock climbing (bouldering): 1 - model 1 (wrong technique); 2 - model 2 (correct technique); $\mathrm{Fp}$ - the force of fastening on the support, equal to the reaction force of the support; $F \Sigma$ is the force holding the body on the support in the hanging; F1, F2, F3, F4 - forces arising from the tension of individual muscles; $A 1, A 2, A 3, A 4, A 5$ - links of the kinematic chain ( $A 5$ - a link resulting from the tension of intertransmitting muscles); Model 1 - the kinematic chain is formed by a small number of links; the force holding the body in the hanging (FI) is due to the forces F1 and F2: $F \Sigma=F 1+F 2$ : Model 2 - the kinematic chain is formed by a large number of links; the force holding the body in the hang (F5) is due to the strength of the links $A_{1}, A_{2} A_{3}, A_{4}: F_{\Sigma}=$ $F_{1}+F_{2}+F_{3}+F_{4}$

climbing and included special exercises. The exercises were aimed at developing the skill of turning on all the links of the kinematic chain when performing a hang. For this, exercises were used in a closed kinematic chain. A closed kinematic chain assumes the work of all its links: the muscles of the shoulder girdle, trunk, legs. The skill of working all the muscles of the kinematic chain is one of the basic conditions for correct hanging technique in climbing and preventing injuries. Therefore, to form this skill, we used exercises in a closed kinematic chain.
The program also included a focus on correct hanging technique while climbing.

Influence of the intervention program on the technique of performing one-arm hang and on traumatism of students

Before the experiment, the average expert assessment of the hanging technique in rock climbing by athletes from the control group was $19.05 \pm 0.78$, in the intervention group this value was $19.5 \pm 0.87(\mathrm{p}>0.05)$. Before the experiment, the groups did not differ significantly in terms 
of hanging technique. After the experiment, the average value of the expert assessment among the athletes in the control group was $26.8 \pm 0.83$, and in the intervention group $-32.15 \pm 1.18(\mathrm{p}<0.05)$ (Table 2). This indicates a positive effect of the use of injury prevention means in rock climbing on the formation of a biomechanically functional hang technique.

The results of biomechanical analysis of the hanging technique in rock climbing in terms of the angle between the shoulder and the collarbone confirmed the results of an expert assessment of the hanging technique on one arm. The correlation coefficient between the value of the considered angle and the value of the expert assessment was $-0.95(p<0.001)$ (Table 2$)$. This testifies to the coincidence of the subjective assessment of the hanging technique by experts and the objective indicators of the hanging technique.

There was a significant decrease in the angle between the shoulder and the clavicle in the athletes of the intervention group $(p<0.001)$. In the control group, these changes are not significant $(\mathrm{p}>0.05)$ (Table 2). The groups before the experiment did not differ significantly in terms of the angle between the shoulder and the collarbone ( $p>$ 0.05 ). After the experiment, significant differences were found between the control and experimental groups in terms of the angle between the shoulder and the clavicle (Table 2).

Before the experiment, the value of the angle between the shoulder and the collarbone in the control group athletes was $131.91 \pm 24.71$, in the intervention group this value was $137.18 \pm 6.40(p>0.05)$. This indicates that before the experiment, the groups did not differ significantly from each other. After the experiment, the average value of the angle between the shoulder and the clavicle in the athletes of the control group was $127.23 \pm 9.87$, and in the athletes of the intervention group $-116.32 \pm 14.55$ $(p<0.05)$ (Table 2). This indicates a positive effect of the application of the developed program on the formation of biomechanically functional hanging technique.

The influence of the prior art on the number of injuries during the experiment was also determined by the method of Cochran and Mantel-Hansel (Table 3). A high reliability of the influence of the level of technique proficiency on the number of injuries was found $(p<0.001)$ (Table 3 ). Since prior to the experiment, the groups did not significantly differ among themselves in terms of the level of climbing technique, it can be noted that at the end of the experiment the level of technique significantly affects the number of injuries.

Table 3. Influence of the level of technique on the number of students' injuries during rock climbing lessons

\begin{tabular}{lll}
\hline Treatment method name & $\begin{array}{l}\text { Chi-Squared } \\
\left(\boldsymbol{\chi}^{\mathbf{2}}\right)\end{array}$ & $\mathbf{p}$ \\
\hline Cochran's & 65,070 & 0,000 \\
Mantel-Haenszel & 52,990 & 0,000 \\
\hline
\end{tabular}

The total number of all recorded elbow injuries during 1 year of the experiment was 29 in the control group and 5 in the intervention group. The number of registered injuries of varying complexity was as follows: in the control group: 12 - Mild Degree, 10 - Moderate Degree, 7 - Severe Degree; in the intervention group: 3 - Mild Degree, 2 - Moderate Degree, 0 - Severe Degree (Table 4).

The risk (Injury rate) of elbow injuries Mild Degree per 1000 AEs during 1 year of the experiment in the control group was $1.82(95 \% \mathrm{CI}, 1.071 ; 2.403)$, in the intervention group - 0.5 (95\% CI, 0.064; 0.979). The incidence rate ratio for cohort (injuries $=$ no) for Mild Degree elbow injuries was $0.786(0.643 ; 0.962)$ (Table 4). The incidence rate ratio for cohort (injuries $=$ yes) for Mild Degree elbow injuries was 3.636 (1.106; 11.959)

Table 2. Indicators of hanging technique fulfillment in rock climbing by athletes from the control group $(n=44)$ and the intervention group $(n=40)$ before and after the experiment

\begin{tabular}{|c|c|c|c|c|c|}
\hline \multirow[b]{2}{*}{ Technique indicators } & \multirow[b]{2}{*}{ Group } & $\bar{X} \pm S$ & $\bar{X} \pm S$ & \multirow[b]{2}{*}{$\mathbf{t}$} & \multirow[b]{2}{*}{$\mathbf{p}$} \\
\hline & & $\begin{array}{l}\text { Before } \\
\text { experiment }\end{array}$ & $\begin{array}{l}\text { After } \\
\text { experiment }\end{array}$ & & \\
\hline \multirow{2}{*}{ Expert review, points } & CG & $19,05 \pm 3,72$ & $26,8 \pm 3,9$ & 2,01 & $<0,01$ \\
\hline & IG & $19,5 \pm 3,9$ & $32,15 \pm 5,31$ & 5,54 & $<0,001$ \\
\hline \multirow{2}{*}{$\begin{array}{l}\text { Statistical indicators of comparison of the control } \\
\text { and experimental groups according to the expert } \\
\text { evaluation of the technique }\end{array}$} & $\mathrm{t}$ & 0,38 & 3,69 & - & - \\
\hline & $\mathrm{p}$ & $>0,05$ & $<0,01$ & - & - \\
\hline \multirow{2}{*}{$\begin{array}{l}\text { The angle between the shoulder and the collarbone, } \\
\text { degrees }\end{array}$} & CG & $131,91 \pm 24,71$ & $127,23 \pm 9,87$ & 0,82 & $>0,05$ \\
\hline & IG & $137,18 \pm 6,40$ & $116,32 \pm 14,55$ & 5,87 & $<0,001$ \\
\hline \multirow{2}{*}{$\begin{array}{l}\text { Statistical indicators of comparison of the control } \\
\text { and experimental groups according to the expert } \\
\text { evaluation of the technique }\end{array}$} & $t$ & 0,97 & 2,82 & - & - \\
\hline & $\mathrm{p}$ & $>0,05$ & $<0,05$ & - & - \\
\hline $\begin{array}{l}\text { Relationship between expert judgment of technique } \\
\text { and the angle between the shoulder and the } \\
\text { collarbone }\end{array}$ & $r$ & $-0,95$ & & - & $<0,001$ \\
\hline
\end{tabular}


(Table 4). The probability of getting a Mild Degree elbow injury in the control group was 3.636 times higher (95\% $\mathrm{CI}=1.106-11.959, \mathrm{P}$ (Fisher) $=0.017$ ) compared with the intervention group (Table 4). The risk (Injury rate) of moderate elbow injuries per 1000 AEs during 1 year of the experiment in the control group was 1.52 (95\% CI, 0.247; $1.883)$, in the intervention group - 0.33 (95\% CI, 0.089; 1.272). The Incidence rate ratio for cohort (injuries $=$ no) for Moderate Degree elbow injuries was 0.813 (0.683; 0.968); $\mathrm{P}=0.039$ ) (Table 4). The incidence rate ratio for cohort (injuries $=$ yes) for Moderate Degree elbow injuries was 4.545 (1.059; 19.506) (Table 4). The probability of getting a Moderate Degree elbow injury in the control group was 4.545 times higher $(95 \% \mathrm{CI}=1.106-11.959$, $\mathrm{P}($ Fisher $)=0.017)$ compared with the intervention group (Table 4). The risk (Injury rate) of severe elbow injuries per thousand AEs during 1 year of the experiment in the control group was $1.06(95 \% \mathrm{CI}, 0.134 ; 1.795)$, in the intervention group - 0 (no severe injuries were found in the intervention group). The incidence rate ratio for cohort (injuries $=$ no) for Severe Degree elbow injuries was 0.841 (0.739; 0.956); $\mathrm{P}=0.02$ ) (Table 4). The incidence rate ratio for cohort (injuries $=$ yes) was not determined for Severe Degree elbow injuries in the control group and the intervention group, since no Severe Degree injuries were recorded in the intervention group (Table 4).

The odds (Odds Rate) of getting Mild Degree elbow injuries in the control group is 0.375 , in the experimental group - 0.081 . The chance of getting low-complexity elbow injuries in the control group was 4.625 times higher $(95 \% \mathrm{CI}=1.143-27.324, \mathrm{P}(\chi 2)=0.028)$ compared to the experimental one (Table 4).

The chance (Odds Rate) of getting a Moderate
Degree elbow injury in the control group is 0.294 , in the intervention group - 0.053 (Table 4). The chance (Odds Rate) of getting injuries and diseases of Moderate Degree in the control group is 5.588 times higher $(95 \%$ $\mathrm{CI}=1.143-27.324, \mathrm{P}(\chi 2)=0.028)$ compared to the intervention group (Table 4).

The chances of getting injuries and diseases of the elbow of high complexity in the control group is 0.159 , in the experimental group - 0 (in the intervention group, not a single injury or disease of the elbow of severe complexity was found) (Table 4). The probability of not getting injured (intervention group / control group) is 0.841 (95\% $\mathrm{CI}=0.739-0.956, \mathrm{P}$ (Fisher) $=0.008$ ) (Table 4). Injury odds ratio for Severe Degree injuries was not determined because no Severe Degree elbow injuries were identified in the intervention group.

Thus, our study showed that the use of our program reduces the risk of injury (Incidence rate) of elbows in student climbers. The incidence rate of injury is reduced for mild, moderate and severe elbow injuries. Significant risk reduction was found for moderate and severe injuries. Severe elbow injuries were not detected in the experimental group during the course of the experiment.

\section{Discussion}

The hypothesis of the effectiveness of the use of exercises Exercises in a closed kinematic chain for the prevention of injuries in climbing has been confirmed. We obtained a significant reduction in injury risk (Injury rate) in terms of Incidence rate ratio and Odds Rate Ratio for Mild elbow injuries, Moderate Degree and Incidence rate ratio (injuries $=$ no) for Severe Degree injuries. It should be noted that no severe elbow injuries were found in the

Table 4. Indicators of risk of injuries and diseases of the elbow in the Control $(n=44)$ and Intervention Groups $(n=40)$ groups during the year

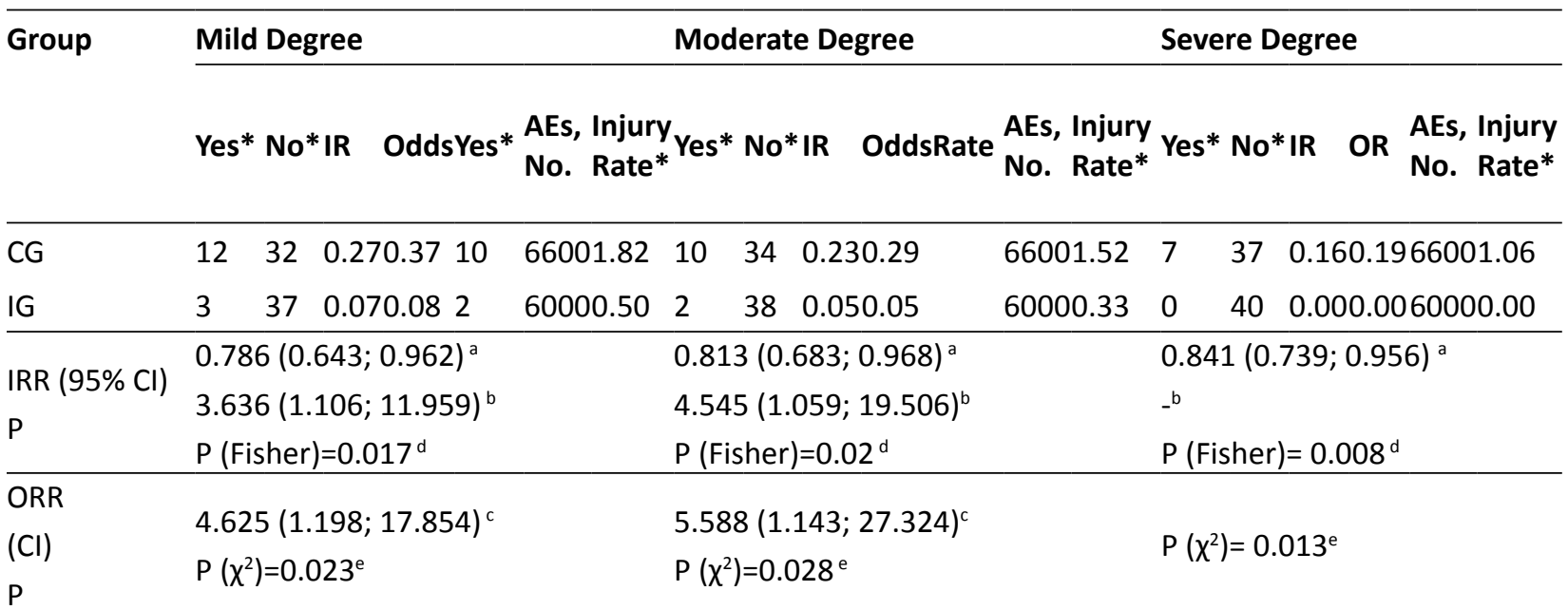

NOTE: CG - Control Group; IG - Intervention Group; * - Yes - the number of people injured; no - the number of people who were not injured; IR - Injury rate (without indicating the number of injuries per 1000 AEs); IRR - Incidence rate ratio; $A E s-$ athlete $\times$ exposure (training sessions, competitions); ${ }^{*}$ Injury rate indicates the number of injuries per

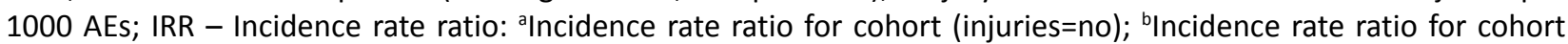
(injuries=yes); ' $\mathrm{ORR}$ - Odds Rate Ratio for group (control/intervention); $\mathrm{Cl}$ - confidence interval (Lower bound; Upper

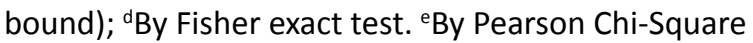


intervention group. The data on the effectiveness of the use Exercises in a closed kinematic chain for the injury prevention of students during rock climbing have been confirmed [21-24].

Our study confirmed the provisions formulated in our previous works $[25,26]$. For skilled climbers, the total hanging force is significantly greater than that for nonskilled climbers. This is due to the fact that in qualified athletes, not only the muscles of the upper limb (as in unskilled athletes), but also the muscles of the trunk and legs are involved in maintaining the hanging position on one arm when climbing. These muscles create additional links in the kinematic chain. Accordingly, the upper limb has a lower load compared to the technique of unskilled athletes. This provided a theoretical basis for the formation of the most effective climbing technique, which ensures the achievement of a sports result and prevents injuries. Therefore, to activate not only the muscles of the arms, but also the muscles of the legs and trunk, it is advisable to use exercises in a closed kinematic chain.

Our study confirmed the theory of Bernstein [26], from which it can be traced that the basis of injury prevention is the effective organization of movement control from the side of the central nervous system. Our methodology is built according to the interaction of various levels of movement organization [18]. Signals from muscle proprioceptors are predominantly received at level A. These signals indicate the degree of muscle tension and signals from the organ of balance. Therefore, level A is one of the main levels for ensuring movement without injury. Muscle tone and intermuscular coordination are one of the main conditions for injury preventing. Exercises in closed kinematic chains affect primarily these aspects of level A, and this is a confirmation of Bernstein's theory $[26,28,29]$.

Level B receives signals from muscle, articular, connective, and skin proprioceptors. In case of violations / decrease in the functionality of level $\mathrm{B}$, a selection of non-optimal synergies is observed when performing movements. Level B also serves to provide injuryfree movement. Muscle synergy is also one of the key prerequisites for injury prevention. Exercises in a closed kinematic chain affect level B. This is a confirmation of Bernstein's theory [18]. Our study also confirmed the theory of motor control [31-36], according to which the effective organization of movement control by the central nervous system is the basis of injury prevention.

Thus, the work confirms the data on the need for the formation of biomechanically grounded technique of movements for the injury prevention in sports, the theory of movement control on the need to form a rational technique to prevent injuries $[16,17]$. The work expanded and supplemented the data $[21,23]$ on the use of exercises in closed kinematic chains for the prevention of injuries in various sports, in particular, in rock climbing.

Our work also includes a climbing injury prevention program. This is new data. As far as we know, our study is one of the first to develop and validate a climbing injury prevention program.

\section{Conclusions}

1. The main parameters of the one-arm hang technique for qualified and unskilled climbers have been substantiated. For qualified climbers, when hanging on one hand, the muscles of the shoulder girdle, torso, and legs are turned on. In unskilled climbers, hanging on one arm is provided only by the muscles of the arm. This increases stress on the ligaments and leads to injury. The angle between the shoulder and the collarbone is greater for unskilled versus qualified athletes.

2. The use of exercises in closed kinematic chains helps to improve the technique of the one-arm hang in rock climbing. There was a significant improvement in the results of biomechanical analysis of the hang technique in rock climbing among athletes of the intervention group: after the experiment, the angle between the shoulder and the clavicle decreased significantly in the athletes of the intervention group ( $\mathrm{p}<0.001)$, while in the control group these changes were not significant $(p>0.05)$. A high reliability of the influence of the level of technique proficiency on the number of injuries was found $(p<0.001)$.

3 . The total number of all recorded elbow injuries during 1 year of the experiment was 29 in the control group and 5 in the intervention group. The number of recorded injuries of varying complexity was as follows: in the control group: 12 - low complexity, 10 - medium complexity, 7 - high complexity; in the intervention group: 3 - low difficulty, 2 - medium difficulty, 0 - high difficulty. Exercises in a closed kinematic chain reduce the incidence rate of elbow injury in student climbers. The likelihood of injury is reduced for mild moderate elbow injuries ( $p$ $<0.05$ ). The likelihood of not being injured increases for all types of injuries $(\mathrm{p}<0.05)$. Severe elbow injuries were not detected in the experimental group during the course of the experiment.

4. The chance of getting mild elbow injuries in the control group was 4.625 times higher than in the intervention group (95\% CI: 1.198; 17.854). The chance of getting moderate elbow injuries in the control group was 5.588 times higher than in the intervention group (95\% CI: 1.143; 27.324). Exercises in closed kinematic chains are an effective means of forming the correct technique and preventing injuries of students during rock climbing.

\section{Acknowledgements}

The authors are very grateful to all the athletes and coaches who took part in the experiment.

The study was conducted according to the research work on the topic of the Department of Olympic and Professional Sports, Sports Games and Tourism of H.S. Skovoroda Kharkiv National Pedagogical University for 2021-2026: "Development and substantiation of technologies for health promotion and harmonious development of people of different ages and social groups” (№ state registration: 0121U110053).

\section{Conflict of interest}

Authors state that there is no conflict of interest. 


\section{References}

1. Brown S, Hall EE. Evaluating The Effectiveness Of Applying Grief-Response Models To Sport Injury In Collegiate Student-Athletes. Medicine \& Science in Sports \& Exercise. 2018;50(5S):325. https://doi.org/10.1249/01.mss.0000536150.79507.64

2. Hao F, Tang C, Huang D, Cheng B. Pre-test into Legal Issues on the School Sports Injury Accidents. In: Zhang T, editor. Future Computer, Communication, Control and Automation, vol. 119, Berlin, Heidelberg: Springer Berlin Heidelberg; 2012, p. 235-9. https://doi.org/10.1007/978-3-642-25538-0 34

3. Heaney CA, Rostron CL, Walker NC, Green AJK. Is there a link between previous exposure to sport injury psychology education and UK sport injury rehabilitation professionals' attitudes and behaviour towards sport psychology? Physical Therapy in Sport, 2017;23:99-104. https://doi.org/10.1016/j.ptsp.2016.08.006

4. Narvaez WCM, Maldonado GEP, Gomez DIO, Cando EOC. Perception of students on the possible impact of sports injuries on academic performance. Revista Publicando, 2017;4(12):857-64.

5. Clifton DR, Hertel J, Onate JA, Currie DW, Pierpoint LA, Wasserman EB, et al. The First Decade of Web-Based Sports Injury Surveillance: Descriptive Epidemiology of Injuries in US High School Girls' Basketball (2005-2006 Through 2013-2014) and National Collegiate Athletic Association Women's Basketball (2004-2005 Through 2013-2014). Journal of Athletic Training, 2018;53:1037-48. https://doi.org/10.4085/1062-6050-150-17

6. Fraser MA, Grooms DR, Guskiewicz KM, Kerr ZY. BallContact Injuries in 11 National Collegiate Athletic Association Sports: The Injury Surveillance Program, 2009-2010 Through 2014-2015.Journal of Athletic Training, 2017;52(7):698-707. https://doi.org/10.4085/1062-6050-52.3.10

7. Hurtubise JM, Beech C, Macpherson A. Comparing Severe Injuries by Sex and Sport in Collegiate-Level Athletes: A Descriptive Epidemiologic Study. International Journal of Athletic Therapy \& Training, 2015;20(4):44-50. https://doi.org/10.1123/ijatt.2014-0090

8. Jin J. Analysis of sports injuries and the causes in football teaching of college students. Basic \& Clinical Pharmacology \& Toxicology, 2020;126:41-2.

9. Russell K, Selci E, Black B, Cochrane K, Ellis M. Academic outcomes following adolescent sportrelated concussion or fracture injury: A prospective cohort study. PLoS ONE, 2019;14:e0215900. https://doi.org/10.1371/journal.pone.0215900

10.Sang MX. Analysis on the Causes of Sports Injury in College Physical Education and Its Prevention Strategies. 2019.

11. Slater LV, Wasserman EB, Hart JM. Trends in Recurrent Anterior Cruciate Ligament Injuries Differ From New Anterior Cruciate Ligament Injuries in College and High School Sports: 2009-2010 Through 2016-2017. Orthopaedic Journal of Sports Medicine, 2019;7:232596711988386. https://doi.org/10.1177/2325967119883867

12.Sommerfield LM, Harrison CB, Whatman CS, Maulder PS. A prospective study of sport injuries in youth females. Physical Therapy in Sport, 2020;44:24-32. https://doi.org/10.1016/j.ptsp.2020.04.005

13.Sommerfield LM, Harrison CB, Whatman CS, Maulder PS. A prospective study of sport injuries in youth females. Physical Therapy in Sport, 2020;44:24-32. https://doi.org/10.1016/j.ptsp.2020.04.005

14.Lutter C, El-Sheikh Y, Schöffl I, Schöffl V. Sport climbing: medical considerations for this new Olympic discipline. $B r \quad J$ Sports Med, 2017;51:2-3. https://doi.org/10.1136/bjsports-2016-096871

15.LaBella CR, Huxford MR, Grissom J, et al. Effect of neuromuscular warm-up on injuries in female soccer and basketball athletes in urban public high schools. Archives of Pediatrics and Adolescent Medicine, 2011;165(11):1033- 1040. https://doi.org/10.1001/archpediatrics.2011.168

16.Parkkari J, Taanila H, Suni J, Mattila VM, Ohrankämmen $\mathrm{O}$, Vuorinen $\mathrm{P}$, et al. Neuromuscular training with injury prevention counselling to decrease the risk of acute musculoskeletal injury in young men during military service: a population-based, randomised study. BMC Med, 2011;9:35. https://doi.org/10.1186/1741-7015-9-35

17.Weineck J. Optimal training: performance-physiological training with a special focus on training for children and young people. 17., neu überarbeitete Auflage. Balingen: Spitta; 2020.

18.Bernstein NA. The coordination and regulation of movements. Oxford : Pergamon Press; 1967.

19.Zinchenko VP. Nikolai Bernshtein: From reflexes to models of the future. Voprosy Psikhologii, 2004(6):123-7.

20.Feigenberg IM. Long way of author to readers (about N.A. Bernshtein works). Uspekhi fiziologicheskikh nauk, 2004;35(4):78-81.

21.Coppack RJ, Etherington J, Wills AK. The effects of exercise for the prevention of overuse anterior knee pain. The American Journal of Sports Medicine, 2011;39(5):940-948. https://doi.org/10.1177/0363546510393269

22.Augustsson RJ, Esko A, Thomee R, Svantesson U. Weight training of the thigh muscles using closed vs. open kinetic chain exercises:Acomparison of performance enhancement.Journal of Orthopaedic \& Sports Physical Therapy, 1997;27(1):3-8. https://doi.org/10.2519/jospt.1998.27.1.3

23.Lee J-H, Jintae H. Comparison of the Thickness of the Neck Flexor Between Open and Closed Kinetic Chain Exercises During Chin-in Movemen. PNF and Movement, 2020;18(3):333-41.

24.Roh JS. Effects of Isokinetic Strength Exercise of the Hemiparetic Knee Joint on Lower Extremity Sensorimotor and Gait Functions in Patients With Chronic Stroke: Open Kinetic Chain Versus Closed Kinetic Chain. Physical Therapy Korea, 2019;26(2):49-60. https://doi.org/10.12674/ptk.2019.26.2.049

25.Kozin S, Safronov D, Kozina Z, Kniaz H, Proskurnia O, Prontenko K, Lahno O, Goncharenko V, Kholodniy A. Comparative biomechanical characteristics of one-arm hang in climbing for beginners and qualified athletes. Acta of Bioengineering and Biomechanics, 2020;22(1):57-67. https://doi.org/10.37190/ABB-01440-2019-03

26.Kozin SV. Biomechanical substantiation of the technique of hanging in rock climbing. Health, sport, rehabilitation. 2019; 5(1): 25-35. https://doi.org/10.34142/HSR.2019.05.01.03

27.Kozin S, Kozina Z, Korobeinik V, Cieślicka M, Muszkieta R, Ryepko O, Boychuk Yu, Evtifieva I, Bejtka M. Neuromuscular training for injury prevention of students-rock climbers studying in the specialty "Physical Education and Sports": a randomized study. Journal of Physical Education and Sport, 2021;21(Suppl. issue 2):1251-1259.

28.Kozin S, Cretu M, Kozina Z, Chernozub A, Ryepko O, Shepelenko T, Sobko I, Oleksiuk M. Application closed kinematic chain exercises with eccentric and strength exercises for the shoulder injuries prevention 
in student rock climbers: a randomized controlled trial. Acta Bioeng Biomech. 2021;23(2):54-62. https://doi.org/10.37190/ABB-01828-2021-01

29.Kozin S, Kozina Z, Korobeinik V. Injury prevention of rock climbers (Neuro-muscular training for injury prevention of rock climbers based on biomechanical analysis of the one-arm hang). [Internet]. Encyclopedia platform; 2021. [updated 2020 Jun 15; cited 2021 Apr 21]. Available from: https://encyclopedia.pub/9802

30.Knowles S, Marshall SW, Guskiewicz KM. Estimating rates and risks in sports injury research. $J$ Athl Train. 2006;41:207215.

31.Attwood MJ, Roberts SP, Trewartha G, England ME, Stokes KA. Efficacy of a movement control injury prevention programme in adult men's community rugby union: a cluster randomised controlled trial. BrJSports Med, 2018;52:368-74. https://doi.org/10.1136/bjsports-2017-098005

32.Dingwell JB, Bohnsack-McLagan NK, Cusumano JP. Humans control stride-to-stride stepping movements differently for walking and running, independent of speed. Journal of Biomechanics, 2018;76:144-51. https://doi.org/10.1016/j.jbiomech.2018.05.034
33. Newell KM, Liu Y-T. Collective Variables and Task Constraints in Movement Coordination, Control and Skill. Journal of Motor Behavior, 2021;53:770-96. https://doi.org/10.1080/00222895.2020.1835799

34.Santuz A, Ekizos A, Janshen L, Mersmann F, Bohm S, Baltzopoulos V, et al. Modular Control of Human Movement During Running: An Open Access Data Set. Front Physiol, 2018;9:1509. https://doi.org/10.3389/fphys.2018.01509

35.Seth A, Hicks JL, Uchida TK, Habib A, Dembia CL, Dunne JJ, et al. OpenSim: Simulating musculoskeletal dynamics and neuromuscular control to study human and animal movement. PLoS Comput Biol, 2018;14:e1006223. https://doi.org/10.1371/journal.pcbi.1006223

36.Zou L, Yeung A, Li C, Chiou S-Y, Zeng N, Tzeng H-M, et al. Effects of Mind-Body Movements on Balance Function in Stroke Survivors: A Meta-Analysis of Randomized Controlled Trials. International Journal of Environmental Research and Public Health, 2018;15:1292. https://doi.org/10.3390/ijerph15061292

\section{Information about the authors:}

Serhii Kozin; http://orcid.org/0000-0003-1351-664X; kozin.serenya@gmail.com; H.S. Skovoroda Kharkiv National Pedagogical University; Kharkiv, Ukraine.

Zhanneta Kozina; (Corresponding Author); http://orcid.org/0000-0001-5588-4825; zhanneta.kozina@gmail.com; H.S. Skovoroda Kharkiv National Pedagogical University; Kharkiv, Ukraine.

Marina Jagiello; https://orcid.org/0000-0001-5591-4537; wjagiello1@wp.pl; Gdansk University of Physical Education and Sport; Gdansk, Poland.

Marko Joksimović; http://orcid.org/0000-0003-4232-5033; nicifor007@outlook.com; Institute of Sports and Sports Medicine; Podgorica, Montenegro.

\section{Cite this article as:}

Kozin S, Kozina Zh, Jagiello M, Joksimović M. Injury prevention of student rock climbers based on the formation of rational technique of movements: a randomized control trial. Physical Education of Students, 2021;25(5):307-318. https://doi.org/10.15561/20755279.2021.0507

This is an Open Access article distributed under the terms of the Creative Commons Attribution License, which permits unrestricted use, distribution, and reproduction in any medium, provided the original work is properly cited http://creativecommons.org/licenses/by/4.0/deed.en

Received: 09.09.2021

Accepted: 25.10.2021; Published: 30.10.2021 